\title{
ACERCA DEL QUINTO TEMPLARIO. \\ LA ORDEN DEL TEMPLE Y LOS CONDES DE BARCELONA EN LA CONQUISTA DE AL-ANDALUS
}

\author{
ANTONI VIRGILI \\ Universitat Autònoma de Barcelona \\ (Bellaterra, Barcelona)
}

\begin{abstract}
SUMARIO
1. Ramón Berenguer IV y los Templarios.- 2. Los Templarios en la conquista de los valles del Ebro y del Segre.- 3. Recapitulación.- 4. Abreviaturas, siglas, fuentes y referencias bibliográficas.
\end{abstract}

"Et de conquisitione terre sarracenorum quintam partem vobis concedo et decimum totum ex his que parti mee pertineant". Este fragmento corresponde al documento del acuerdo firmado en Girona, el 27 de noviembre de 1143, entre Ramon Berenguer IV, Conde de Barcelona y Príncipe de Aragón, y los representantes de la Orden del Temple. Contiene el conjunto de donaciones y privilegios ofrecidos a la Orden como compensación por la renuncia a su parte del reino de Aragón, que había sido concedido a las Órdenes Militares por Alfonso el Batallador mediante testamento. El pacto, no sólo liquidaba el arduo contencioso planteado por el testamento del rey aragonés, sino que consolidaba la presencia de los Templarios en la península y aseguraba su contribución en las operaciones militares de conquista de al-Andalus. Los distintos historiadores que han estudiado este importante y trascendental documento - que trataremos con detalle a lo largo del artículo- interpretan la frase como si se tratara de la

"Anuario de Estudios Medievales", 27 (1997) 
concesión territorial de una quinta parte de las regiones conquistadas. Mi vano intento de encontrar esta porción territorial de la Orden en Tortosa y su término a raíz de la conquista de 1148 -aún siendo la primera tan solo cinco años después del acuerdo aludido- me llevó a revisar el documento en su conjunto. Después de haberlo sometido a un atento examen con el complemento de documentación contemporánea, sugiero una interpretación alternativa del texto. Los Templarios se sitúan, de esta forma, en el contexto más preciso para ilustrar y entender su contribución en la implantación del orden feudal sobre las regiones de conquista reciente. No obstante, empezaré por reconstruir, aunque de forma sintética, los antecedentes.

$$
* * * *
$$

Las Órdenes militares del Hospital, Santo Sepulcro y Temple surgen en Oriente, durante el siglo XI, estrechamente relacionadas con la Reforma Pontifical y las Cruzadas. La escasa estabilidad de los reinos cruzados en Siria y Palestina y la necesidad de captar recursos humanos y financieros las llevó a extenderse por el occidente feudal ${ }^{1}$.

En el año 1113, la Orden del Hospital de San Juan de Jerusalén fue reconocida por el papa Pascual II mediante una bula considerada como su auténtica carta fundacional (M. BONET, 1994, 5). La Orden del Temple debe su origen a una cofradía fundada en Jerusalén, el año 1119, bajo el impulso de Hugo de Payens; el Concilio de Troyes (1128) significó su aprobación canónica y la inmediata redacción de la regla. Los distintos privilegios papales a favor de las Órdenes contribuyeron a su extraordinario desarrollo posterior y fortalecieron enormemente su poder, sobre todo, gracias a la independencia que lograron respecto a los poderes laicos y eclesiásticos ${ }^{2}$.

Las primeras fundaciones y encomiendas de las Órdenes militares en el occidente feudal se establecieron en los dominios de los reyes de

\footnotetext{
'Su objetivo inicial no era crear fundaciones estables en Europa, sino captar recursos y también hacer proselitismo (J. M. SANS, 1996, 81, 87, 95-96, 99; L. PAGAROLAS, 1984, 31).

${ }^{2}$ Los papas Inocencio II y Lucio II liberaron al Hospital de la subordinación debida a los obispos, y Anastasio IV estableció que sus iglesias y clérigos dependieran solo del papado (M. BONET, 1994, 5). La bula del papa Inocencio II (1139) concedía a los Templarios el privilegio de no estar sujetos a la jurisdicción eclesiástica, sino directamente del Papa; además, la Orden podía disponer de sus propios clérigos y quedaba libre del pago de diezmos y primicias. En 1145, el papa Eugenio III otorgaba a la Orden el privilegio de edificar sus propios centros de culto. Al respecto, véanse las síntesis de J. M. SANS (1996, 63-72), y de L. PAGAROLAS (1984, 32).
} 
Inglaterra y Francia, así como en Flandes, Sicilia, Pisa, Provenza y la Península Ibérica ${ }^{3}$. Fue aquí, en la península, donde más enraizaron.

Hubo, esencialmente, dos motivos y ambos, muy relacionados. En primer lugar, Alfonso I el Batallador de Aragón optó por legar el reino a las Órdenes del San Sepulcro, del Hospital y del Temple ${ }^{4}$. Esta controvertida decisión planteó un problema complejo que se resolvió entre 1140 y 1143, cuando Ramon Berenguer IV, Conde de Barcelona, se había prometido con Petronila de Aragón. Los pactos entre el Conde y las Órdenes instrumentalizaron, de forma ya definitiva, la participación de éstas en la conquista de alAndalus. Ahí reside el segundo motivo. La conquista se planteó como una auténtica $\mathrm{Cruzada}^{5}$, por lo que el contexto de lucha contra el Islam, muy parecido al de Tierra Santa, no les resultó ajeno. El concurso de las Órdenes en las operaciones no fue meramente testimonial, sino directo y activo mediante la formación de compañías que actuaron casi siempre como una fuerza de choque en los combates y en la primera línea de los asedios. Esta circunstancia les legitimaba todavía más a participar en el reparto del territorio ocupado.

Es en estos pactos donde reside el objetivo preferente de este estudio: cómo y en qué medida participan las Órdenes, y en concreto los Templarios, en la distribución del botín.

Para Ramon Berenguer IV, los compromisos sellados con las Órdenes eran de gran alcance puesto que zanjaban el litigio suscitado por el testamento del Batallador y les comprometía de forma activa en el proceso de conquista de al-Andalus y posterior feudalización del espacio conquistado (M. BONET, 1994, 32).

Los acuerdos del Conde con los Sanjuanistas por una parte, y con los Templarios, por otra, culminaron entre 1140 y 1143 . Iniciaba las

\footnotetext{
${ }^{3}$ Una visión de conjunto, en J. MIRET i SANS (1910, cap. II, ps. 22-47, y III, ps. 47-52). Sobre el Hospital, M. BONET (1994, p.5); sobre el Temple A. J. FOREY (1973, 6-9 y 15-16); J. M. SANS (1977) y (1996, 73-81); L. PAGAROLAS $(1984,33)$.

${ }^{4} \mathrm{El}$ testamento fue otorgado en octubre de 1131 durante el sitio de Bayona. Documento publicado, entre otros por F. MIQUEL (LFM: 6) y J. A. LEMA (Alfonso I: 241 y 242). Fue confirmado por el propio rey en 1134 (J. A. LEMA, Alfonso I: 284). Ver A. J. ForEY (1973, 17).

${ }^{5} \mathrm{~A}$ pesar de que existen precedentes, incluso anteriores a la primera Cruzada sobre Tierra Santa (Barbastro, 1060; al-Mahdīya y Zawila, 1087), fueron Calixto II en 1123 y Eugenio III, hacia 1145, quienes integran al-Andalus en el espacio de Cruzada. La campaña de Tortosa se circunscribe en la bula de Eugenio III, publicada por P. de BOFARULL (CODOIN, IV: CXXVIII).
} 
negociaciones con los primeros mediante una carta sin fecha ${ }^{6}$, que algunos autores datan en 1137, cuyo destinatario ha sido atribuído erróneamente al Temple, advierte M. BONET (1994, 33). El Conde se comprometía a adjudicar a los Sanjuanistas lo siguiente: la manutención suficiente para una comunidad de diez freires, y además, la ciudad de Daroca con sus habitantes y pertenencias; Lope Sánchez de Belchite con sus dos castillos de Osa y Belchite y su honor de Cutanda; en la ciudad Zaragoza les hace entrega de un cristiano, un musulmán y un judío con sus posesiones y la superficie de tierra que puedan labrar un par de bueyes durante un año; la cuarta parte de la villa de Cuarte, cercana a Huesca; y finalmente, la décima parte de todo lo que pueda adquirir en Hispania, en censos, en honores o en cualquier cosa ("Item illis concedo decimam partem omnium que in Ispania adquirere potero tam in censu quam in honore vel in aliquibus rebus").

Subrayaría dos aspectos concernientes a este conjunto de compromisos. En primer lugar, que los derechos prometidos a la Orden de San Juan por haber renunciado a su parte del reino aragonés son distintos e inferiores a los ofrecidos al Temple. En segundo lugar, que alguno de los bienes inicialmente asignados a los Sanjuanistas serán librados a los Templarios, como se verá ${ }^{7}$. Según los acuerdos definitivos, los Hospitalarios fueron compensados por los Condes-reyes con heredades patrimoniales, concesiones pecuniarias y privilegios específicos ${ }^{8}$, que aumentaban con el desarrollo de la conquista (M. BONET, 1994, 31-80). Los Templarios también recibieron honores de carácter territorial (immuebles y distritos castrales), pero, además, se beneficiaron de derechos de tipo general aplicables sobre regiones pendientes de conquista y que resultaron ser superiores a los primeros a medida que se iban concretando.

\footnotetext{
${ }^{6}$ Documento publicado por P. de Bofarull (CODOIN, IV: CLIII). Al respecto, véase M. BONET $(1994,33)$. A. J. Forey $(1973,21-22)$. J. M. SANS $(1977,36-37 ; 1996,89-90)$ y L. PAGAROLAS $(1984,40-41)$ atribuyen al Temple la dirección de la misiva condal, a pesar de no indicarlo explícitamente, ni de existir ningún maestre general templario con el nombre de Raimundo durante las fechas en que debió redactarse la carta: ("Raimundo Dei gratia militie Iherosolimitane magistro et cunctis fratribus cismarinis et ultramarinis"); seguramente se trata de Raimundo de Puy, o de Podio, maestre del Hospital entre 1120 y 1158 o 1160 . El documento no recoge ninguna mención al maestre templario Roberto de Craon.

${ }^{7}$ Tal vez, ahí resida el motivo por el que los autores aludidos hayan atribuído al Temple la dirección de la letra de Ramon Berenguer.

${ }^{8}$ Ver M. BONET (1994, 31 y ss). Los documentos han sido publicados, entre otros, por F MIQUEL (LFM: 12, 10 y 11, según el Orden cronológico), y por J. ALTURO (Santa Anna: 228, $233,235)$.
} 


\section{RAMON BERENGUER IV Y LOS TEMPLARIOS.}

El convenio entre el Conde y los Templarios llegó al término de un proceso más lento y complejo que el anterior. Los historiadores que se han ocupado del tema están de acuerdo en situar los primeros pasos en la constitución de una paz y tregua a beneficio de la Orden'. Ramón Berenguer IV, acompañado del conde Ermengol VI de Urgell y del conde Ponç Hug de Empúries, amparaba mediante tregua de Dios a los caballeros de la Milicia que desearan establecerse en sus dominios, asegurándoles la protección de sus castillos, villas, casas y demás bienes. También, les otorgó privilegios procesales, y con el resto de caballeros que le acompañaban, se comprometieron a conceder a los freires, caballos y el arnés para el combate.

El pacto definitivo se firmó en Girona, el 27 de noviembre de 1143, y se reflejó en un documento que contiene los distintos compromisos y cláusulas ${ }^{10}$. Después de un preámbulo, donde se pone de relieve la relación entre Hispania y la Orden a través de la Cruzada, se expone la relación de asignaciones condales. Entre las donaciones territoriales destacan la transferencia de los castra de Monzón y Montgai en franco alodio; los castra de Xalamera y Barberà; el honor de Lobo Sánchez de Belchite; el castrum de Remolinos y los derechos del propio Conde en el castrum de Corbins.

Ramon Berenguer también se comprometía a librar rentas y numerario: mil sueldos anuales en Zaragoza, el diezmo de las rentas y censos procedentes de las cosechas, de los derechos legales y de las justicias ("tam de expletis quam de omnibus consuetudinibus" rectis et de iusticiis"), inclusive en caso de alienación ("si forte aliquid de honore meo dare, vendere vel inpignorare mihi contigerit decimum vestrum salvum et liberum vobis remaneat"), así como en el caso de nuevas adquisiciones de recaudación de derechos y rentas ("De omnibus siquidem que Deo iuvante iuste

\footnotetext{
${ }^{9}$ Documento publicado por Bofarull (CODOIN, IV: XI), y por G. GonZalvo (1994: 11). Al respecto, SANS TRAVÉ $(1977,33-35 ; 1996,85-87)$ y L. PAGAROLAS $(1984,37-38)$.

${ }^{10}$ Sólo se conserva un traslado (ACA: Pergamins de Ramon Berenguer IV, 159), publicado, entre otros, por P. de BOFARULL (CODOIN, IV: XLIII).

"Suscribimos la propuesta de J. MASSIP $(1984,69)$ de otorgar al término consuetudo el significado de "tasa, exacción" (no impuesto). Más propiamente, serían los ingresos procedentes de los derechos establecidos por la costumbre: los "derechos legales" desde el punto de vista de quien los percibe.
} 
conquirere potero decimum quiete et libere vobis concedo"). Al dar al término conquirere el significado de "conquistar", la historiografía ha entendido este fragmento como la promesa condal de transferir a la Orden el diezmo en las tierras conquistadas a al-Andalus ${ }^{12}$. Asimismo, la frase "in omnibus vero cavalcatis vel expedicionibus Ispanie de vestris scilicet hominibus quintas vobis perpetuum dimitto et dono", ha sido interpretada como una concesión de la quinta parte del botín capturado por miembros de la Orden durante las cabalgadas o expediciones de saqueo sobre regiones de al-Andalus. Sin embargo, no se trata de librar la quinta parte del mismo, como puede dar a entender el texto, sino la totalidad, puesto que el Conde tenía derecho a percibir el quinto obtenido en tales campañas; el resto correspondía a los protagonistas de la hueste. Este quinto, en cuanto a regalía, es lo que el Conde adjudica a los Templarios ${ }^{13}$.

Pero, sin duda, la concesión más relevante, por lo que podía representar en un futuro próximo, era la porción de las regiones de alAndalus que recibirían por derecho de conquista ("Et de conquisitione terre sarracenorum quintam partem vobis concedo et decimum totum ex his que parti mee pertineant"). Entre los autores que se han ocupado de la cuestión sólo existe una línea interpretativa del texto a propósito del compromiso: la promesa de dotar a los Templarios, al procederse al reparto del botín, con la quinta parte de las tierras de al-Andalus conquistadas con su concurso ${ }^{14}$.

\footnotetext{
${ }^{12}$ J. M. SANS $(1977,39 ; 1994,22-23 ; 1996,92)$. L. PaGAROlas $(1984,42)$. En ningún caso se hace distinción entre este párrafo y otro posterior sobre el diezmo. A. J. FOREY (1973, 22) también generaliza: $a$ tenth of royal revenues.

${ }^{13}$ Parece que hacia 1130, Alfonso el Batallador había ofrecido al Temple este mismo privilegio (A. J. FOREY, 1973, 9). En 1195, el rey otorga una concesión de idénticas características a los Sanjuanistas, y el texto no puede ser ya más claro: “... quintam quod ego habeo (...) et consuevimus habere et recipere de illis qui de terra intrant ad devastandum Ispaniam et terram sarracenorum, sed omne ius meum ...". Documento publicado por DelaVille (Cartulaire, I, d. 960). Al respecto, M. BONET (1994, 40).

${ }^{14} \mathrm{~A}$. J. ForeY, en su exhaustivo estudio, sin duda el más completo sobre el Temple en la Corona de Aragón, escribe al respecto: "... a fifth of all lands conquered from the Moors" $(1977,22)$. Los autores más relevantes que se han ocupado del establecimiento de los Templarios en Catalunya suscriben esta interpretación: J. M. SANS $(1977,39), \quad$ ".. i de les terres que conquerís als musulmans, una quinta part, a més d'una dècima de les que corresponien al comte...", y él mismo se expresa en términos parecidos (1994, 22-24; 1996, 92-93). L. Pagarolas $(1984,42), "$... la desena de totes les terres que ell pogués adquirir; la cinquena part de les que reconquerís als sarraïns, a més de la desena de les que corresponien al comte". M. BONET $(1994,33)$, también comparte esta tesis, aunque más superficialmente por no constituir en centro de interés de su estudio: "... el Temple debía recibir la quinta parte de las tierras conquistadas y del botín, además de otros bienes".
} 
La interpretación, igual que antes, parte del hecho de atribuir al término conquisitione, derivado de conquirere, el significado de "conquista".

Una cláusula final especifica que las transferencias condales a la iglesia serían excluidas del conjunto de bienes sujetos a la transferencia del diezmo a la Orden ("Quod autem de decimis superius statutum est ita etiam firmamus sicut superius legitur salva in omnibus donatione que ecclesiis facta est").

La colección de privilegios terminaba con la cesión de importantes exenciones e inmunidades. La milicia podía proceder a la construcción de castillos y fortificaciones contra mauros. El Conde no podría establecer, bajo ningún concepto, una paz con los andalusíes de forma unilateral; de hacerlo, tendría que ser con la anuencia de las jerarquías templarias ("pacem non facturum cum mauris nisi vestro consilio"). Esta disposición concuerda con el carácter guerrero de la Orden y confirma la posición de Hispania (alAndalus) como objetivo militar (A. J. FOREY, 1973, 23). Finalmente, los Templarios eran eximidos del pago de tasas por el tránsito de mercancías en todos los dominios condales ("Dono vobis iterum atque concedo quod de vestra propria causa per totam terram meam nulla ledda, nulla consuetudo, nullum passaticum accipiatur").

La firma de las principales dignidades de la $\operatorname{Orden}^{15}$ ponía de relieve la conformidad de las autoridades de la misma en la solución del contencioso planteado por el testamento del Batallador. El Papado tardó todavía algunos años en dar su aprobación definitiva. En efecto, a pesar de la presencia de Guido, legado de Inocencio II, en la asamblea de Girona en 1143, fue Eugenio III, en 1150, quien finalmente hizo público el reconocimiento papal a la cuestión, ratificado poco después por el papa Adrián IV ${ }^{16}$.

Quisiera puntualizar dos aspectos, aparentemente sin relación, concernientes a los derechos de la Orden en las regiones conquistadas. El primero es de carácter textual y se refiere al hecho de reflejar la promesa de la décima parte condal en dos párrafos distintos. No deja de sorprender una reiteración de este signo en un documento tan preciso. Cabe observar, en segundo lugar, que la transferencia de una quinta parte de cualquier región

\footnotetext{
${ }^{15}$ Estampan la firma de aprobación fray Éverard des Barres, gran maestre de Francia, fray Pere de Rovera, gran maestre de Provenza e Hispania, entre los más relevantes.

${ }^{16}$ Respecto a la aprobación papal y a sus posteriores confirmaciones, pueden verse J. M. SANS $(1977,40-41 ; 1996,94)$ y L. PAGAROLAS $(1984$, ps. 42-43). La documentación papal en relación al Temple, en R. HIESTAND (1972-1984).
} 
incorporada por conquista, más la décima parte del sector condal, se ha de concretar por escrito, puesto que no puede prescindirse de unos límites territoriales concretos que han de ser debidamente especificados con el fin de evitar posteriores disputas. La eventual pérdida de este documento, circunstancia nada improbable, no tendría porqué borrar todas las huellas de dicha porción territorial, ya que la quinta parte de cualquier espacio territorial es una proporción considerable, sea cuál fuere su superficie total. Los rastros de este significativo espacio se encontrarían -insisto, en el caso de haberse perdido el documento de origen- en la concesión de cartas de población, donaciones a censo, contratos de explotación, etc. Cuando nada, o muy poco, de todo esto existe, o no es percibido en el curso de una investigación, hay que buscar una explicación que justifique esta ausencia. Mi propuesta pasa por revisar el documento de 1143 y sugerir una línea interpretativa alternativa a la tradicional.

A pesar de que el latín medieval vulgar admite el significado de "conquistar" y "conquista" para los términos conquirere y su derivado conquisitione (que provienen de cum quaero), propongo traducirlos en su acepción clásica. Es decir, por "adquirir, obtener, e incluso recaudar", y "adquisición, recaudación, cobro de tributos", respectivamente. Así, cuando el Conde se comprometió a dar el diezmo de las rentas y censos que percibía, y añade de todo aquello que conquirere potero, se refiere a las posibles adquisiciones de nuevos derechos de recepción de rentas.

En cuanto a la quintam partem de conquisicione no significaría "tener que otorgar sistemáticamente la quinta parte de los territorios", sino el porcentaje de las rentas que iban a obtenerse en terre sarracenorum, es decir, en las regiones conquistadas sobre las que el Conde ejercerá la potestas. Así, tiene sentido la frase que sigue al fragmento anterior sin pausa, por la cual el Conde expresa el deseo de añadir el diezmo de todo lo que le pertenece en las regiones conquistadas. Esta décima parte, pues, no coincide con la del texto anterior. No es una reiteración de la misma concesión, ni una redundancia textual. Dicha mención al diezmo especifica que el producto de las conquistas territoriales, como generadoras de nuevas fuentes de renta, también estarán sujetas a la transferencia del diezmo condal a la Orden Templaria, exceptuando de dicha obligación las dotaciones a la iglesia, como ya se ha indicado. En 1156, el papa Adrián IV confirmó los pactos entre la Orden y Ramon Berenguer: "quintam quoque partem ex terris 
sarracenorum ex tunc in posterum divina clementia capiendis" ${ }^{17}$. Tal vez, una lectura precipitada podría dar a entender que se refiere a la quinta parte de las tierras. La preposición de ablativo aclara, sin embargo, su sentido de procedencia, con lo cual el texto se refiere a la quinta parte de las rentas procedentes de las tierras conquistadas, según establece el instrumento, refiriéndose al documento de 1143.

Hay otros argumentos que justifican los aludidos significados de conquirere y sus derivados. En toda la documentación examinada, próxima en el espacio y en el tiempo, y parecida en su formulario, no hemos sabido localizar estos términos para designar la conquista, ya en sus formas verbales, ya sustantivadas. Sin excluir la posibilidad de su empleo en otros documentos, la mayoría de los consultados se sirven del verbo capio/ere $e^{18}$ en sus diversas formas, y de sus derivados, como captione, para referirse a la conquista. Con el término obsidio/nis ${ }^{19}$ se designa el momento preciso del asedio a una ciudad o una fortaleza. No se excluyen otros términos, pero

\footnotetext{
${ }^{17}$ Bula pontificia publicada por P. de Bofarull (CODOIN, IV: XC).

${ }^{18}$ Un documento del proyecto de Ramon Berenguer III de conquistar Tortosa en 1098 reza "...Tortuosam civitatem capere poterit ..." (ACA: pergs. Ramon Berenguer III, núm. 51). La conquista de diversas ciudades o regiones recogidas en los Cronicones de Tortosa y Ripoll emplean la forma "... capta est" (VILLANUEVA, VL, Chronicon Dertusense, II, vol V., ps. 236240; Chronicon Rivipullense, ps 241-249. Caffaro titula el fragmento de su Crónica sobre las conquistas de Almería y Tortosa en 1147 y 1148 Ystoria captionis Almarie et Tortuose (edición de L. T. Belgrano, Annali Genovesi). El documento de consagración de la catedral románica de Tortosa en 1178 se refiere con entusiasmo a la conquista de la ciudad "capta est Dertusa" (VIRGILI, DCT: 301). En 1146 los genoveses se comprometen ad "obsidendam et expugnandam Tortosam" y acuerdan el reparto de todo lo que "cum comite ceperimus" (IMPERIALE, CDRG 168). En los mismos términos se expresan más adelante "(...) in obsidione alicuius civitatis, sive illam capiamus (...)", y en lo relativo a Tortosa, "(...) Tortuosam ceperint" (IMPERIALE CDRG: 169). Culminada la conquista, Ramon Berenguer IV concede privilegios comerciales a los genoveses por su contribución "in captione Tortose" (IMPERIALE, CDRG: 191). Asimismo, el papa Adrián IV se expresa en estos términos al referirse a "ex terris (...) capiendis", en el documento aludido (P. de BOFARULL, CODOIN, IV: XC). Para la conquista de Lleida se reproducen las mismas expresiones: "capta fuit civitas Ilerde" (MIRET i SANS, 1910, 71); el Conde de Urgell hizo donaciones a sus vasallos "in captione Ilerde" (MIRET i SANS, 1910, 89). Para la conquista de Miravet también se utiliza el capio/ere (P. de BOFARULL, CODOIN, IV LXXVII), y lo mismo sobre la conquista de Siurana, cuando en 1172, "post captionem Ciurane", se procedió a la reconstrucción de sus antiguos límites (P. de BOFARULL, CODOIN, VIII: XIV).

${ }^{19}$ Además de algunos ejemplos reflejados en la nota anterior, el término in obsidione se encuentra en muchos documentos sobre Tortosa (IMPERIALE, CDRG: 190; BISSON, 1984, docs, 142 y 143; etc). También el asedio de Lleida (MIRET i SANS, 1910, 66; VIRGILI, DCT: 15). Antes, en 1147, encontramos a "Raimundo, comite Barchinonensi obsidente Almariam" (MIRET i SANS, 1910, 88).
} 
ya mucho menos corrientes ${ }^{20}$. Desde luego, insisto, conquirere y conquisitione en ninguna otra ocasión.

Según esta propuesta de lectura del documento, el quinto templario no ha de tomar necesariamente una dimensión territorial, sino una participación de este porcentaje sobre las rentas procedentes de las regiones conquistadas $^{21}$. La cláusula que excluye los bienes librados a la iglesia de ser computados en el diezmo templario tiene que ser leído en este mismo sentido. De otro lado, si se trata de participar de las rentas y no del espacio territorial, basta con el documento redactado, en 1143, en Girona; no precisa de más puesto que no hay espacio que limitar. Además, esta particularidad explicaría la ausencia de documentación posterior orientada a dirigir la explotación del territorio con cartas de población y otros tipos de contratos.

Sin embargo, tampoco tiene por qué ser rechazada la posibilidad de compensar la quinta parte de las rentas mediante la concesión de un determinado espacio territorial. Pero, la diferencia es clara y decisiva, cuando ocurre, ya que se redacta un documento y se hace constar. Varias razones impulsaran, como veremos, esta estrategia.

Para ilustrar los argumentos sugeridos más arriba he centrado la investigación en las conquistas de los valles del Ebro y del Segre, ya que son las más inmediatas a los pactos establecidos, y porque a su vez, es donde los contenidos de los mismos se cumplen con más rigurosidad.

\footnotetext{
${ }^{20}$ Hay expresiones todavía más genéricas para referirse a una conquista futura: "quando Deus dederit ei de terris Ispanie" (P. de BOFARULL, CODOIN, IV: XX).

${ }^{21}$ De esta cuestión existen precedentes con los que se establecen evidentes paralelismos. El establecimiento de los "bárbaros" en las provincias del Imperio Romano de Occidente mediante la hospitalitas originó problemas de interpretación a propósito de la forma adoptada. A la tendencia inicial, que se inclinaba por un reparto de territorios, W. GoFFART (1980) propuso una asignación de la recaudación fiscal. Al respecto, véase M. BARCELó (1988). Parece que fue éste, también, el criterio seguido en los asentamientos del yund sirio en al-Andalus después de sofocar la revuelta bereber del año 741 (P. CHALMETA, 1975, pp. 37-42)
} 


\section{LOS TEMPLARIOS}

\section{EN LA CONQUiSTA DE LOS VAlLES DEL EBRO Y DEL SEGRE}

Después de las alianzas con las Órdenes, la primera campaña militar dirigida por Ramon Berenguer IV fue la conquista de Tortosa. Distintas fuentes han puesto de relieve la contribución activa de los Templarios en el asedio de la ciudad de Turtūša ${ }^{22}$. Aunque menos visible en los textos, también se ha documentado la presencia de los Hospitalarios ${ }^{23}$.

No cabe duda que una parte del convenio, como era la intervención de las Órdenes en la operación, se cumple. Evidentemente, falta la segunda parte, consecuencia directa y justificación de la primera: la participación en el reparto del botín. La Orden del Hospital recibió importantes dominios en la actual comarca del Montsià, además de un solar en Tortosa y un huerto en sus inmediaciones ${ }^{24}$.

En cuanto a los Templarios, no hay indicios para suponer que el pacto de 1143 haya perdido su vigencia. En consecuencia, tendrían que percibir la quinta parte de la ciudad y de la región a ella vinculada ${ }^{25}$, según la interpretación clásica del texto aludido ${ }^{26}$. De aceptar este supuesto, ignoramos cómo realizó el Conde la transferencia y desconocemos el documento donde se delimita el espacio que corresponde a la quinta parte, urbana y rural, del conjunto. De haberse tratado de un territorio concreto debía de haber sido explicitado por escrito y firmado por ambas partes, si

\footnotetext{
${ }^{22}$ Fuentes tan dispares como la crónica de Caffaro, según el cual los freires y los cruzados ("angli, militibus Templi et cum multis aliis alienigenis") asediaban una de las puertas (ed. de L. T. BELgRANO, Annali, p. 86). Otras referencias a la presencia templaria en MIRET i SANS $(1910,60)$; L. PaGarolas $(1984,56-57)$, y M. L. Ledesma $(1964,52)$.

${ }^{23}$ Véanse M. L. LedeSma (1964; 1967); J. M. Font Rius (1953), y A. J. Forey (1984).

${ }^{24} \mathrm{En} 1150$, les fue dada Amposta que se convirtió en encomienda y en cabeza de la Castellanía; luego Ulldecona constituída, también, en encomienda. Al respecto, M. BONET (1994: 279-285).

${ }^{25} \mathrm{~A}$ grandes rasgos, corresponde a las actuales comarcas del Baix Ebre y del Montsià según los límites establecidos en la carta de fueros de noviembre de 1149, otorgada por Ramon Berenguer IV: de la Roca Folletera hasta el mar, y del Coll de Balaguer hasta el río de Ulldecona (río Sénia). Documento publicado, entre otros, por J. M. FONT RIUS (CPFC: 75), A. Altisent (DP: 120) y A. ViRGILI (DCT: 20).

${ }^{26}$ E. BAYERRI (1957, 8 y 17), a partir de P. de Bofarull y de MiRet i SANS $(1910,61)$ apuesta por una división ternaria: un tercio para los genoveses, otro para Guillem Ramon de Montcada y otro para el Conde. Éste, de su porción, "dio luego el quinto a los Templarios, se entiende en concepto de feudo, pero reservándose desde el primer momento el dominio directo y eminente". Nadie y en ningún caso aporta documentación para justificar estas afirmaciones.
} 
se hubiese aceptado. A pesar de la relevancia de tan significativa ausencia, ni tan siquiera se plantea ¿Se ha perdido o, tal vez, no se redactó jamás?.

El documento no existe, sea cuál sea la causa de su carencia, pero en cambio, se menciona esporádicamente illo quinto fratrum. Los autores antes reseñados persisten en una concepción territorial del quinto templario, a propósito de la región de Tortosa. Para L. Pagarolas, "Els Templers (...) continuaven amb el cinquè de tots els béns del sobirà. Cal fer notar que la qüestió de les jurisdiccions sobre la ciutat, palesa principalment en la potestat d'administrar justícia i en la percepció sobre determinats llocs, no fou mai ben definida (...). Del domini inicial del comte, els Templers en reberen el cinquè, el qual s'engrandí amb motiu de la compra feta pel mateix als genovesos" (1984, 59-60). Más adelante insiste en el carácter espacial de la porción: "(...) comptava la nova Comanda de Tortosa amb unes terres inicials adquirides per dret de conquesta, que calia permutar per tal d'arrodonir-les i beneficiar-se'n millor de llur conreu. (...) Els Templers de la ciutat de l'Ebre, ja des d'un principi, gaudien del senyoriu sobre les cases i possessions que, arran dels tractats dels anys 1143 i 1149 fets amb Ramon Berenguer IV, els pertocaven a la ciutat i terme, i que suposaven en un primer moment un cinquè del total de la Senyoria" $(1984,78)$. El uso del concepto "quinto de la señoría" sorprende tanto por su contrariedad respecto al resto del párrafo donde el autor apuesta claramente por un quinto territorial, como por su ambigüedad. J. M. SANS i TRAVÉ $(1996,355)$, con un discurso parecido, tampoco es lo bastante explícito. Ya J. MASSIP se había pronunciado en parecidos términos, a partir del documento de la controversia entre el Conde y Guillem Ramon de Montcada ${ }^{27}$.

No obstante, cabría preguntarse sobre los motivos que impulsan a la Orden a formar un dominio territorial en la región de Tortosa si, en realidad, partían de un patrimonio tan considerable como el veinte por ciento del espacio, a pesar de su opacidad y de la dificultad de percibirlo entre los centenares de documentos conservados. El pormenorizado estudio de L. PAGAROLAS sobre la creación y evolución de la encomienda (1984, 73 y ss.) muestra el alcance y el ritmo del proceso. Durante la segunda mitad del siglo XII, la Orden efectúa unas cincuenta operaciones de compra de inmuebles: 26 hasta 1170, para las cuales invirtió alrededor de 2500 morabatines de oro;

\footnotetext{
27" Ramon Berenguer IV dóna al Temple el quint de les utilitats de la seva part, d'acord amb el pacte i promesa que li havia fet abans de la conquesta" (J. MASSIP, 1984, 58). El autor no se pronuncia sobre el contenido del término utilitats.
} 
17 compras en la década central del período, con una inversión cercana a los 1000 morabatines; el ritmo cae vertiginosamente en las dos últimas décadas del siglo con 7 actos de compra a razón de 240 morabatines. De manera simultánea, percibe 17 donaciones de inmuebles, 3, 8 y 6, respectivamente, en los intervalos cronológicos aludidos. La mayor parte de las parcelas se concentraban en la vega fluvial, ante la ciudad de Tortosa, a la derecha del Ebro. La abrumadora mayoría del número de compras efectuadas respecto a las donaciones recibidas no hace más que confirmar el interés de la Orden en la formación de un dominio territorial en la región de Tortosa ${ }^{28}$.

En rigor, los textos muestran un quinto templario mucho más relacionado con la percepción de rentas que con una determinada porción patrimonial. En consecuencia, el hecho de que el quinto se refiera a las rentas y no al territorio da pleno significado a que la Orden decida formar un dominio territorial de inmediato.

El 4 de noviembre de 1153, los Templarios renuncian a la quinta parte que les correspondía del castillo de Amposta y de la torre de la Candela a favor de los Sanjuanistas que habían recibido el distrito de manos del Conde en 1150: "dimittimus et difinimus (...) quintam partem nostram de illo castello Emposta et de toto eius termino et de ipsa Candela et de termino eius (...) et de nostro iure dimitimus et tradimus nostram quintam partem"29. Queda claro, por tanto, que el porcentaje de la Orden comprendía el espacio acotado por la carta de fueros de Tortosa del año 1149.

El resultado del reparto de Tortosa no convencía a Guillem Ramon de Montcada, al considerar que el Conde no había cumplido la promesa de asignarle el tercio de Tortosa. Denunciado el caso a la Curia, Ramon Berenguer alegó no poder entregar aquello que no era suyo, es decir, el tercio de la república de Génova y la "parte quinta templariorum", con lo

\footnotetext{
${ }^{28} \mathrm{~A}$ pesar de no resultar éste el lugar más adecuado, no podemos prescindir, cuando menos, de plantear la estrategia utilizada en la explotación de este dominio, habida cuenta que se trata de una zona de cultivo intensivo, y sólo se contabilizan siete contratos de censo entre la documentación reunida, cuatro de los cuales se formalizan en la última década del siglo. Por otra parte, merece ser subrayado el poco interés de la Orden por formar un patrimonio urbano. No se registra ni una sola casa, ni un solar por edificar en el conjunto de las compras efectuadas en Tortosa. Este hecho contrasta con la orientación de la Orden en Huesca donde posee un considerable dominio urbano, como ha puesto de relieve A. CONTE (1992; 1994), y también en Lleida, según consta en la documentación reunida por MIRET i SANS (1910), y por J. LLADONOSA (1991).

${ }^{29}$ Documento publicado por DELAVILLE (Cartulaire, I, 169). Al respecto, véase M. BONET $(1994,35$ y 280$)$
} 
cual a Guillem Ramon le correspondía sólo el tercio de la porción condal ("tercia parte duarum partium minus quinta") ${ }^{30}$. La corte se pronunció a favor del Conde

Progresivamente, el contenido de este quinto se hace más explícito. Vuelve a aparecer en un documento sin fecha que recoge el acuerdo entre la catedral de Tortosa y la Orden sobre la recepción del diezmo en una parte del distrito ${ }^{31}$. Interesa examinar atentamente el texto en su conjunto puesto que posee información de gran importancia. Contiene el reparto de la ciudad de Tortosa entre el Conde y los representantes de la república de Génova, el 29 de junio de 1149. A continuación, reseña la compra de la porción genovesa por parte del Conde $^{32}$, precisando que en ésta el Temple no percibía el quinto, mientras que la iglesia de Tortosa tenía derecho al diezmo. Pasado cierto tiempo, continúa el documento, la Orden compró el quinto de esta tercera parte a Alfonso el Casto. Y, puesto que la iglesia recaudaba el diezmo del quinto en esta tercera parte y no en el de las otras dos partes, se planteó una controversia ante la dificultad de dividir el producto de esta tasa $\mathrm{a}^{33}$. El supuesto galimatías es sólo aparente y proyecta un poco de luz sobre una de las cuestiones más controvertidas: dilucidar si el quinto templario parte del total de los territorios conquistados, o bien de la porción condal, una vez efectuadas las concesiones prometidas con antelación. Se abordará el problema más adelante. Cabe observar, que la iglesia percibía el diezmo en la quinta parte del antiguo tercio genovés, pero no en la quinta parte templaria de los dos tercios restantes, según el documento, en congruencia con los privilegios de la Orden aludidos al principio de este estudio, uno de los cuales era la exención del diezmo.

Si algo no puede ponerse en duda es el carácter rentista y no patrimonial de este quinto templario, bien reflejado en la función de los bailes de cada parte en el momento de dividir el producto de la recaudación:" (...) erat contencio inter baiulos dominorum et baiulos ecclesie quia

\footnotetext{
${ }^{30}$ Documento publicado por P. de BofarULL (CODOIN, IV: LI y CXLVII), y por F MIQUEL (LFM: 464).

${ }^{31}$ Documento publicado por A. VIRGILI (DCT: 18).

${ }^{32}$ Se conserva la documentación de esta operación formalizada en 1153, publicada por $\mathrm{P}$ de BOFARULL (CODOIN, IV: LXXVIII); C. IMPERIALE (CDRG: 243 y 244), y por F. MIQUEL (LFM: 463). El precio reflejado en estos documentos no corresponde al del texto a que nos referimos.

${ }^{33}$ Según el pacto final, la Orden debería entregar a la iglesia dos sueldos mensuales y dos cántaros de aceite anuales en concepto de diezmo.
} 
nesciebant de facili dividere decimam. Tandem habuerunt consilium inter eos et dixerunt quod baiuli Milicie darent baiulo ecclesie (...)".

En una confirmación de la donación del quinto de Tortosa por Alfonso el Casto a la Orden, el carácter rentista de esta porción queda de nuevo bien patente: (...) "quintam partem tocius civitatis Tortose sicut eam habeo et teneo et omnium reddituum atque proventuum eius et terminorum ipsius tam ex mari quam ex terre provenientium rebus et causis"; i de tot el que en surti, "per baiulum meum et baiulum ipsorum fratrum et aliorum qui ius habent fident, congregantur et postea antequam dividentur vel aliqui de eis minuerat accipiant fratres domus Milicie Templi integriter et sine diminutione aliqua quintam partem et in perpetuum eam habeant $(\ldots)^{134}$.

En marzo de 1182, se produce la cesión de la soberanía de Tortosa a la Orden por parte de Alfonso el Casto ${ }^{35}$. El documento señala cómo se procedirá al reparto de las rentas desde aquel momento, así como de las dominicaturas y derechos reales y de la Orden exentas de división entre ambas partes. Pero, insiste en el aspecto rentista del quinto templario cuando dispone que la Orden tenga un baile que recaude las rentas de la ciudad y de su término, de tal manera que tanto las rentas que el rey solía percibir como las del quinto de la Orden ("quam de illo quinto fratrum") y de lo que pudiere adquirir en adelante, éste recibiría la mitad. Y, para que no hubiera dudas respecto de lo que tenía cada parte en el momento de producirse esta importante transferencia, en enero de 1184 , se redactó un documento que fijaba con máximo detalle "dominicaturis et exitibus Dertuse civitatis et terminorum"36, es decir, el dominio territorial y los derechos de percepción de renta de cada parte.

El 27 de mayo de 1185, el obispo de Tortosa, Ponç de Monells y la Orden establecieron una concordia relativa a la recaudación y división de diezmos y primicias en el castillo de Horta (Horta de Sant Joan, Terra Alta) $\mathrm{y}$ en las poblaciones del distrito donde los freires hubiesen intervenido su

\footnotetext{
${ }^{34}$ Documento publicado, entre otros, por L. PAGAROLAS (CTT: 57 ), fechado el 22 de marzo de 1175, y por A. I. SÁnCHEZ CASABÓN (Alfonso II: 191).

${ }^{35}$ Las últimas ediciones del texto, de L. Pagarolas (CTT: 75), A. I. SÁnChez Casabón (Alfonso II: 339), y A. VIRGILI (DCT: 335)

${ }^{36}$ Documento publicado por L. Pagarolas (CTT: 81) y por A. I. SÁnChez Casabón (Alfonso II: 382).
} 
repoblación ${ }^{37}$. En dicho documento, hay una referencia al quinto templario de los derechos (quintam vestram) en el supuesto de que el rey decidiera retener o alienar alguna porción del término o de los derechos vinculados a éste.

En diciembre de 1188, la Orden hacía entrega al monasterio de Poblet de su quinta parte en unas casas y un corral que poseían en Torto$\mathrm{sa}^{38}$.

El contenido rentista (tanto del quinto nominal, como del diezmo en todas las rentas condales extraídas de las regiones y territorios de nueva incorporación, sea por conquista o por adquisición) queda nítidamente reflejado en otros dos documentos que muestran la fidelidad y la confirmación de los términos suscritos en el acuerdo general de 1143, en Girona.

El primero de los documentos es una confirmación de la donación de Tortosa a los Templarios por parte del rey Pedro el Católico en $1202^{39}$. La cesión comprende "omnes decimaciones de tota terra mea quam habeo et voluntate Deo adquirere potero, prout habetur et continetur in privilegio ex inde facto supradicte domui et fratribus a domino Raimundo Berenguer, comite Barchinone, avo meo, et etiam a domino Ildefonso, patre meo". Los términos del pacto seguían siendo los mismos; o casi.

En el año 1210, el rey gratifica de nuevo a los Templarios por su contribución en la conquista de los castillos de Ademuz, Castellfabib y Serrella, por lo que insiste en la donación de toda la ciudad y término de Tortosa ${ }^{40}$. Un pasaje del texto se refiere al baile de la Orden y en su función como recaudador y administrador de las rentas, así como de su correcta distribución atendiendo las proporciones de cada señor: "(...) predicti fratres habeant et mittant suum baiulum in civitate (...) qui fideliter accipiat omnes redditus civitatis et terminorum suorum et tam de his omnibus que pater noster et nos ibi soliti sumus accipere quam de illo quinto fratrum atque de omni eo quod ibi melioratum fuerit vel augmentatum (...)".

\footnotetext{
381).

${ }^{37}$ Texto publicado últimamente por L. Pagarolas (CTT: 87) y por A. VIRGILI (DCT:

${ }^{38}$ Documento publicado por J. M. PONS MARQUÉS (CP: 181).

${ }^{39}$ L. Pagarolas (CTT: 123).

${ }^{40}$ L. Pagarolas (CTT: 134).
} 
El 23 de mayo de 1148, se formalizó un pacto entre Ramon Berenguer IV y Ermengol VI de Urgell, mediante el cual unían sus fuerzas para la campaña de Lleida ${ }^{41}$. A grandes rasgos, el contenido es el siguiente. Ramon Berenguer infeudaba a Ermengol la ciudad y el territorio de Lleida. Sin embargo, la repartirían a razón de dos tercios y un tercio, respectivamente, de modo que cada uno podría asignar honores de su porción con absoluta libertad. En el documento consta explícitamente que les correspondía a los Templarios la quinta parte: "Et comes Barchinonensis de duabus partibus suis donet Milicie Templi Iherosolimitani illam quintam partem quam ipsa Milicia debet habere de tota civitate Ilerde et de terminis eius in omnibus". Según el párrafo, esta quinta parte procede del total del espacio delimitado (de tota ...), pero sin perjudicar la porción del Conde de Urgell. De ahí, la frase de duabus partibus en alusión a la porción de Ramon Berenguer. Ermengol no podrá ejercer ningún derecho señorial ni jurisdiccional sobre la porción de la Orden, compensadosele con la commenda del castrum de Ascó.

Los historiadores que se han ocupado de la conquista de Lleida son de la opinión que el quinto templario adquiere, como en Tortosa, una dimensión territorial. J. MIRET i SANS $(1910,66)$ da por hecha la transferencia condal del castillo de Gardeny a la Orden, aunque ningún documento lo avala. J. M. FoNT RIUS se refiere al quinto de una manera vaga e impreci$\mathrm{sa}^{42}$, pero acaba por definirse al afirmar que la Orden, como "beneficiaria de una quinta parte de la ciudad a tenor del mentado convenio, fue distribuyendo también solares y parcelas de sus posesiones" $(1949 / 1985,61)$. Basa esta afirmación en textos aportados por J. MIRET i SANS (1910). El inconveniente estriba en que la mayor parte de los documentos utilizados por MIRET sobre Lleida no son concesiones de solares y parcelas por parte de los Templarios, sino por los Condes de Barcelona y Urgell. J. LLADONOSA, se suma al parecer general al establecer una equivalencia entre el quinto y

\footnotetext{
161).

${ }^{41}$ Documento publicado por P. de BOFARULl (CODOIN, IV: LIV), y por F. MIQUEL (LFM:

${ }^{42}$ Respecto a las dos terceras partes del Conde de Barcelona "detraída la quinta parte prometida a la Orden del Temple" $(1969,807)$; "en Orden a la propiedad dominical el de Urgell recibía una tercera parte de la ciudad, quedando los dos tercios restantes para el Conde de Barcelona, salvo una quinta parte prometida a la Orden del Temple, también como recompensa a su participación militar en la empresa" (1949/1985, 57).
} 
la concesión del castillo de Gardeny, sede de la futura encomienda ${ }^{43}$. A falta de pruebas escritas, el referente sigue siendo MIRET i SANS.

$\mathrm{Ni}$ la vigencia ni la existencia del quinto templario en Lleida pueden ponerse en duda, según los documentos, pero su supuesta vertiente territorial sigue tan invisible como en Tortosa, por lo que, aunque no disponemos de una documentación tan explícita como la del Bajo Ebro, sugiero una lectura en clave de soberanía y derecho, y una participación en las rentas que implícitamente se derivaban de la misma.

Como en Tortosa, la Orden del Temple impulsó un acelerado proceso de formación de un patrimonio ${ }^{44}$. Los territorios que fueron objeto de redacción de una carta de población o de una donación a censo por parte del Temple en el término de Lleida ${ }^{45}$ no parecen tener un origen en el quinto, sino en distritos y heredades recibidos antes de la conquista o incorporados, a través de sendas donaciones o de compras, a partir de ella.

$$
* * *
$$

El fenómeno descrito tiene una réplica similar en el proceso de conquista y feudalización del distrito de Siurana que abraza y rebasa la comarca del Priorat. El quinto templario aparece en un documento expedido el 17 de febrero de 1146 por Ramon Berenguer IV a favor de Berenguer Arnau que recibiría el "castrum et villam de Siurana cum omnibus terminis suis, et dono Sancte Militie Templi quintam partem iamdicte ville et honoris ac terminorum suorum" ${ }^{46}$. El pacto, hecho en previsión a una inminente

${ }^{43}$ J. LLADONOSA, 1955, 83; 1990, 44-45; 1991, I, 131-132.

${ }^{44} \mathrm{La}$ documentación se recogió en el Cartulario de Gardeny, utilizado en su día por MIRET i SANS (1910), y actualmente en curso de publicación preparada por R. Sarobe. P. BERTRAN (1976-1977; 1984), ha publicado documentos de los Condes de Urgell entre los que se encuentran concesiones a los Templarios, así como compras efectuadas por la Orden en el término de Lleida y alrededores. Véanse, también, las tablas de J. LLADONOSA (1991, I, 128201), que reúnen la documentación relativa a las transferencias de inmuebles durante la segunda mitad del siglo XII e inicios del XIII.

${ }^{45} \mathrm{~J}$. M. FONT RiUS ha publicado documentación sobre tres áreas (CPFC: 87, 108, 116). $\mathrm{Al}$ respecto, véase el estudio de X. ERITJA (1996) relativo a los distintos tipos de asentamiento que caracterizan la colonización del territorio. En las tablas de J. LladoNOSA (1991, I, 128201) se encuentran diversas donaciones a censo por parte de los Templarios, pero sólo dos pueden considerarse anteriores a 1160 con seguridad. Quiero subrayar con ello que los inmuebles otorgados a censo no tienen por qué proceder del quinto templario que el Conde tendría que haber transferido de manera inmediata al término de la conquista.

${ }^{46}$ Documento publicado por P. de Bofarull (CODOIN, IV: L). 
conquista de la zona, no tuvo efecto al culminar definitivamente en 1153, es decir, siete años después. Ignoramos la razón de esta modificación, pero no cabe duda de la vigencia del quinto de la Orden, y nada justifica una eventual alteración, sea cual sea el desarrollo de la campaña. La colonización del distrito se efectuó a través de cartas de población, la mayoría de ellas libradas durante las últimas décadas del siglo XII y todo el siglo XIII: los concedientes son quienes han recibido dominios territoriales en el repartimiento. La Orden del Temple no emite ninguna carta. Sus posesiones territoriales iniciales en la zona se limitan a dos yugadas de tierra en el castrum de Marçà, libres y francas, recibidas mediante la cesión del distrito de Miravet. De todas maneras, hay que decir que el quinto templario no vuelve a aparecer en la escasa documentación referente al distrito de Siurana.

En definitiva, cuando se ha podido disponer de documentación abundante, los textos posteriores no han hecho más que confirmar la línea interpretativa que sugerimos para el documento de 1143 que atribuye a la Orden la participación de una quinta parte de las rentas recaudadas en las regiones conquistadas, en virtud de la potestad condal, así como el diezmo de la porción condal. Sin embargo, a pesar del carácter rentista y no patrimonial de este porcentaje, no se excluyen concesiones territoriales que pueden alcanzar incluso distritos enteros. Llegado el caso, este patrimonio consta como un equivalente al quinto.

Así lo refleja, por ejemplo, el amplio término o distrito que encabeza el castillo de Miravet ${ }^{47}$, librado por Ramon Berenguer IV a los Templarios en el año 1153. El conjunto de donaciones territoriales que se agrupan en este importante documento vienen a compensar el derecho al quinto de la Orden en la comarca de la Ribera acabada de conquistar. El texto no puede ser más explícito: "Omnia vero sicut superius scripta sunt dono eis (a los Templarios) et firmiter laudo pro quinta eorum ${ }^{48}$ que ex illis ex donacione mea iure contigit de tota ipsa riparia, scilicet, de Miquinensia usque ad

\footnotetext{
${ }^{47}$ En su extenso perímetro se encontraban los castillos y lugares de Gandesa, Corbera, Algars, Batea, Pinell y Rasquera. Este distrito, tal vez el originario andalusí, abrazaba espacios de las actuales comarcas de la Ribera, Terra Alta, Priorat y Matarranya. Documento publicado por P. de BOFARULL (CODOIN, IV: LXXVII).

${ }^{48}$ El subrayado es mío.
} 
Benihalet sive ad terminos Tortose prout melius et comodius ą̧ eorum utilitatem atque profectum intelligi potest".

Sin duda, la concesión de un distrito territorial con todos sus derechos solventaba las dificultades ocasionadas por la complejidad de la división de las rentas capturadas atendiendo a las proporciones que correspondían a los distintos señores. Pero, sobre todo, obligaba a la Orden a comprometerse de forma activa a impulsar la colonización de los espacios recibidos, a la vez que contribuía a implantar el Orden feudal. Esta colonización se instrumentalizó mediante la concesión de cartas de población. El contraste entre las comarcas de Tortosa, Lleida y Siurana donde el quinto del Temple corresponde a esta proporción de las rentas y la comarca de la Ribera en la cual adquiere una dimensión territorial se refleja, también, en el número de cartas pueblas libradas. En las dos primeras comarcas apenas existen, mientras en la Ribera constituyen el núcleo esencial de la documentación emitida ${ }^{49}$. Esta circunstancia define el papel de la Orden en cada región según el carácter del quinto recibido. Su pasividad en Tortosa, como simple recipiendaria, donde tota la actividad se centra en la formación de su dominio territorial contrasta con el interés de promover la colonización del antiguo distrito de Miravet en la medida que la percepción de rentas depende mayoritariamente de ella ${ }^{50}$.

\section{RECAPITULACIÓN}

La proximidad del pacto de Girona y la precisión de los compromisos adquiridos, explicarían que ni la participación de la Orden en las conquistas de Tortosa y Lleida ni el derecho al quinto de las rentas en las regiones ocupadas se hicieran por escrito. La transferencia condal de este quinto, en definitiva, no se reflejó en ningún documento específico. Asimismo, la ausencia de territorios concretos explicaría que las encomien-

\footnotetext{
${ }^{49}$ La mayor parte de estos documentos han sido publicados por J. M. FONT RIUS (CPFC): Gandesa: 190, 191 y 196; Gandesola: 289; Pinell: 208 y 222; Rasquera: 142; Batea-Algars: $164,165,219,283$, etc. Asimismo, P. ORTEGA (1986-87) ha publicado un documento poblacional de la Pobla de Massaluca, y otro de Rasquera (1991)

${ }^{50} \mathrm{El}$ nivel de renta reflejado en las cartas de población muestran tan solo una parte de la percibida por los señores eminentes, pero no la total capturada a los campesinos. El fenómeno ha sido detectado y estudiado por M. BONET (1991) en la comarca del Montsià, bajo dominio Sanjuanista.
} 
das respectivas se interesaran de forma inmediata en la formación de un dominio patrimonial que no tendría demasiado sentido de haber dispuesto inicialmente de un quinto del espacio territorial. En cambio, tuvo que escriturarse la concesión de la Ribera, ya que, el quinto adquiere una dimensión territorial que convenía delimitar com absoluta precisión.

En Tortosa, los Templarios instalaron su casa-cuartel en Sant Joan, una explanada extramuros actualmente integrada en el casco urbano y conocida con el nombre de barrio o arrabal del Temple. En Lleida se establecieron en el promontorio de Gardeny cuya fortaleza se convirtió en la sede de la encomienda. Ni en un caso ni en el otro consta por escrito la transferencia del inmueble ni su toma de posesión. Esta circunstancia coincide con el hecho de que el quinto de la Orden no adquiere un carácter patrimonial. No cabe especular con la posibilidad de una pérdida de sendos documentos para justificar su ausencia.

Quedan todavía cuestiones no totalmente resueltas. Por un lado, cabe interrogarse si el quinto templario computa a partir del total de las rentas del distrito, o bien de la porción condal deducidas las fracciones comprometidas con los otros conquistadores. MIRET i SANS $(1910,61)$ se inclina por una participación de la porción condal que en Tortosa se reduce a un quinceavo del total, es decir la quinta parte sobre el tercio de Ramon Berenguer IV, una vez separados los tercios del Común de Génova y de Guillem Ramon de Montcada. Pero, ningún texto sostiene esta interpretación. En rigor, ninguna cláusula del documento de 1143 prevé recorte alguno y, en consecuencia, el quinto tendría que partir de la totalidad del espacio conquistado como porción nominal, sea cuál fuere el criterio aplicado en el reparto ("et de conquisitione terre sarracenorum quintam partem vobis concedo"). El documento es clarísimo cuando el Conde tiene la intención de hacer otros partícipes de su porción ("addo vobis omne decimum tocius terre mee ... decimum totum ex his que parti mee pertineant"). De otro lado, la precisión recogida en el pacto de la conquista de Lleida que explicita un quinto del total parece definitiva. Las distintas confirmaciones posteriores avalan, todavía más, esta interpretación. El rey Alfonso el Casto, al referirse a la donación paterna, afirma haber cedido la quinta parte de Tortosa y del resto de al-Andalus ("quintam partem Tortose et alterius Ispanie") ${ }^{51}$. La mayor

\footnotetext{
${ }^{51}$ Documento publicado por L. PAGAROLAS (CTT: 57).
} 
parte de la historiografía acepta que el quinto templario parte de la totalidad del territorio ocupado, es decir, el veinte por ciento del conjunto ${ }^{52}$.

El pacto de 1143, en efecto, establece en un quinto la proporción a percibir por la Orden del Temple en los territorios de al-Andalus incorporados por conquista a los dominios del Conde de Barcelona. Ninguna cláusula contempla replantear la cuestión ni ninguna razón justifica recortes, por lo menos, a corto plazo. A pesar de ello, es cierto que algunos documentos posteriores, de redacción un tanto confusa en algunos párrafos, pueden plantear dudas acerca de la parte sobre la que va a computarse dicho quinto $^{53}$. Sin embargo, conviene subrayar que muchas de estas dudas tienen su origen, por una parte, en los privilegios de las Órdenes, exentas de satisfacer el diezmo, y, por otra, en la cláusula que excluía las donaciones condales a la iglesia de los bienes sujetos a la transferencia de la décima a la Orden del Temple. Por ello, cuando se producen cambios en el ejercicio de la potestad surgen conflictos entre las instituciones afectadas ${ }^{54}$. Por otro lado, si los Templarios no hubiesen percibido íntegramente el quinto de Tortosa en el mismo instante de la conquista, no tendría sentido la compra de una parte en la porción genovesa, una vez adquirida por el Conde de Barcelona. La Orden, visto su proceder en todas la causas legales, hubiera exigido una concesión gratuita de haber sido conforme al derecho.

Otra premisa que no ofrece duda alguna es que la transferencia del quinto templario en ningún momento puede perjudicar las porciones asignadas a los aliados militares del Conde, como los genoveses en Tortosa o el Conde de Urgell en Lleida. Tanto los unos como el otro han de percibir, y perciben, el tercio de la ciudad y del territorio que han contribuido a conquistar. Así, los Templarios reciben un quinto del total, pero deducido de la porción del Conde de Barcelona. El documento previo a la conquista de Lleida es, sin duda, el más explícito: el Conde, de duabus

\footnotetext{
${ }^{52}$ A. J. Forey (1973, 25). L. Pagarolas $(1984,42,58-64,75$ y 78; 1994). J. C. SHIDELER (1987, 102-104 y 183-188). Asimismo, la documentación posterior, empleada a lo largo de este estudio (vid. infra), parece confirmar este supuesto.

${ }^{53}$ Estas dudas afloran, especialmente, a causa de la necesidad de incorporar nuevos aliados militares por parte del Conde, la retribución de cuyos efectivos les convertirá en nuevos partícipes del repartimiento; y también al producirse cambios significativos en el mapa señorial de la región, caso de Tortosa, por ejemplo, con la venta de la porción genovesa en 1153, o la posterior cesión real al Temple en 1182 .

${ }^{54} \mathrm{Las}$ controversias suscitadas al respecto generaron documentación abundante. En Tortosa, esta cuestión ha sido estudiada por L. PAGAROLAS (1984, 132-152); A. VIRGILI (1993; 1994), y M. BONET $(1994,285-292)$.
} 
partibus librará el quinto de "tota civitate (...) et de terminis eius in omnibus".

La cuestión planteada es relevante porque, según los criterios adoptados, la recaudación se distribuirá en unos niveles muy distintos. Aplicando el cálculo sexagesimal ${ }^{55}$ resultan estos supuestos:

1. Si el quinto templario parte del total se establecerá en 72:360. El tercio de Génova en Tortosa o de Ermengol en Lleida es invariable: 120:360. En consecuencia, la porción condal quedará en 168:360.

2. Si el quinto se deduce de la porción condal, después de haber descontado el tercio que invariablemente permanece en 120:360, la parte de la Milicia se reduce a 48:360 y la porción condal aumenta a 192:360.

El interés de precisar esta cuestión no termina aquí, puesto que Guillem Ramon de Montcada había firmado un convenio según el cual percibiría la tercera parte de Tortosa de Ramon Berenguer IV. Es evidente que el barón de Montcada esperaba recibir 120:360, pero el Conde se basó en su porción ${ }^{56}$ que, naturalmente, sería distinta según se entienda el quinto del Temple. Habida cuenta de que la corte dio la razón al Conde, Guillem Ramon tuvo que conformarse con lo mínimo que podía exigir: el tercio de la parte condal, es decir, 56:360, menos de la mitad de la previsión inicial. No es este el lugar más idóneo para plantear si el Conde practicó una estrategia de compensación gradual en favor del barón a medida que iba acaparando derechos, como el tercio genovés a partir de 1153 .

Otro problema de difícil respuesta es conocer cuáles eran los derechos condales de percepción de rentas. Presumiblemente, por lo menos, serán los relacionados con el ejercicio de la soberanía que constan en los textos bajo el ambiguo término de consuetudines, además de las lezdas y los peajes.

Resulta complejo, en resumen, reconstruir el desarrollo del proceso de distribución de las rentas recaudadas en las regiones conquistadas a partir de los pactos que precedieron las campañas. De lo que no parece haber dudas es de los cambios efectuados después de las primeras experiencias en

\footnotetext{
${ }^{55} \mathrm{La}$ razón de adoptar este sistema de cálculo reside en que es el único que admite la divisibilidad de totas las proporciones que aparecen, tanto si parten directamente del total como de una porción.

${ }^{56} \mathrm{De}$ ahí las quejas de Guillem Ramon que denunció al Conde ante su propia corte, en Barcelona, como ya se ha indicado, lo que generó un tenso proceso judicial, según se desprende de la gravedad de las acusaciones vertidas entre ambos magnates.
} 
Tortosa y Lleida. Por estas razones, el quinto templario será progresivamente compensado mediante un equivalente territorial con el cual se resolvían los problemas de distribución y de absentismo. Durante el reinado de Alfonso el Casto el patrimonio de la Orden creció de forma espectacular aunque no había participado en el repartimiento del Bajo Aragón, hasta el punto de percibir, quizá, una participación superior al quinto (A. J. FOREY, 1973, 2629).

Claro está que de haberse mantenido semejante ritmo de concesiones -el quinto más una participación en la porción condal-, la Orden se habría convertido en una entidad feudal todavía más poderosa de lo que fue, que no fue poco. Tal vez, con el fin de limitar el patrimonio templario Pedro el Católico y, sobre todo, Jaime I introdujeron cambios muy significativos a propósito del reparto de las zonas conquistadas: el botín sería proporcional a la contribución militar de cada participante ${ }^{57}$. Esta disposición frenaría de forma significativa el crecimiento del patrimonio templario en las futuras conquistas $^{58}$, pero, esto no fue obstáculo para que la Milicia siguiera contribuyendo de una forma notable al arraigo del orden feudal en las regiones sobre las que se proyectó la expansión. ¿Acaso la formación del ejército de conquista, la previsión de un reparto del territorio, la división de la soberanía y de las rentas que suponía y el control del trabajo campesino con la consiguiente captura de renta que comporta, pueden admitir otra calificación?. T. N. BISSON (1985/1997) lo percibió con claridad al señalar que Ramon Berenguer IV, antes de conquistar el sur y el oeste de la actual Catalunya, casi había perdido el control sobre sus antiguos dominios patrimoniales. Por tanto, la conquista era su única salida. Integrado alAndalus en el espacio objeto de Cruzada por parte del Papado a cambio del compromiso de dotar a las sedes episcopales resultantes (restauratio), la

\footnotetext{
${ }^{57}$ A. J. ForeY (1973, 31-36) sostiene que fue esta la razón por la cual los Templarios no obtuvieron en Mallorca ni en Valencia unas concesiones tan significativas como en los valles del Ebro y del Segre. Y concretamente afirma que durante el asedio de Borriana, "he (Jaume I) revoked the order's right to a fifth of lands conquered from the moors" $(1973,33)$.

${ }^{58}$ A. J. FOREY $(1973,26-28 ; 1992)$ señala que, para no herir susceptibilidades y no perjudicar a la iglesia -tal vez para evitar amonestaciones procedentes del Papado- los monarcas impulsaron la fundación y el establecimiento de nuevas Órdenes, a las que también dotaron generosamente, con la finalidad de evitar que crecieran en su poder. Podría ser el caso de la Orden de Monjoy, de paso fugaz, puesto que se disolvió en 1196. El Temple se constituyó en heredero de su patrimonio, con lo que se desvaneció el proyecto inicial del Conde-rey. Pero las bases para limitar el poder templario estaban ya esbozadas, y se materializaron, un poco más tarde, con Jaime I.
} 
conquista disponía de todos elementos (legitimación ideológica, recursos militares y financieros, etc) para convertirse en una empresa imparable. Y, el papel desempeñado por los Templarios, por convicción y por propio interés, ha sido ya suficientemente puesto de relieve.

\section{Abreviaturas, Siglas, FUENTES Y REFERENCIAS BIBLIOGRÁFICAS}

ACA. Arxiu de la Corona d'Aragó. Barcelona.

Alfonso I: vid. LEMA PUEYO, J. M.: 1990.

Alfonso II: vid. SÁNCHEZ CASABÓN: 1995.

Altisent, A.: 1993. Diplomatari de Santa Maria de Poblet, vol. I (960-1177), Barcelona.

Alturo, J. 1985. L'Arxiu Antic de Santa Anna de Barcelona del 942 al 1200. Fundació Noguera, Barcelona.

BARCEló. M.. Feudalismo e Historia Medieval, "Arqueología Medieval. En las afueras del 'medievalismo', Ed. Crítica, Barcelona, pp. 21-52.

BAYERRI, E. 1957. Historia de Tortosa y su comarca. Tortosa, vol. VII.

BELGRANo, L. T. ed. 1890. Annali Genovesi di Caffaro e de'suoi continuatori, I. "Fonti per la Storia d'Italia". Roma.

BERTRAN, P. 1976-77. Donacions de la comtessa Dolça d'Urgell als ordes religiosos (1148-1210). "Analecta Sacra Tarraconensia", 49-50, ps. 41-50. Barcelona.

BERTRAN, P. 1984. Per a un diplomatari d'Ermengol VII (1154-1184). Els ordes militars al comtat d'Urgell. "Ilerda", XLV, ps. 147-174. Lleida.

Bisson, T. N. 1985/1997. La crisi de les franqueses catalanes (1150-1200). "L'impuls de Catalunya. L'època dels primers comtes-reis (1140-1225)", ps. 75100. Eumo. Vic.

Bofarull, P. 1848. Colección de documentos inéditos del Archivo de la Corona de Aragón. Vol. IV. Barcelona.

BofARUll, P. 1851. Colección de documentos inéditos del Archivo de la Corona de Aragón. Vol. VIII. Barcelona.

BONET, M. 1991. Las cartas de población y la renta feudal en el dominio hospitalario del Montsià (s. XIII). "Miscel.lània d'homenatge al P. Agustí Altisent". Tarragona, ps. 551-571.

Bonet, M. 1994. La Orden del Hospital en la Corona de Aragón. Poder y gobierno en la Castellanía de Amposta (ss. XII-XIV). CSIC. Madrid.

CAFFARO. Ystoria captionis Almarie et Turtuose. Vid. BELgRANo, L. T.

CDRG: vid. IMPERIALE. 
Chalmeta, P. 1975. Concesiones territoriales en al-Andalus (hasta la llegada de los almorávides), "Cuadernos de Historia. Hispania", CSIC, 6, pp. 1-90.

CODOIN: vid. BOFARULL, P.

CONTE, A. 1992. Trets precapitalistes en l'economia templera a la Corona d'Aragó. L'exemple d'Osca. "L'Avenç", 161, ps. 34-55.

CONTE, A. 1994. Trazas precapitalistas n'a esplotazion d'opatrimonio templerio de Uesca. "Actes de les primeres jornades sobre els Ordes Religioso-militars als Països Catalans (segles XII-XIX)", ps. 80-97. Tarragona.

CP: vid. PONS MARQUĖS, J. M. 1938.

CPFC: vid. FONT RIUS, J. M.: 1969.

CTT: vid. PAGAROLAS, L.

DCT: vid. VIRGILI, A. 1997.

Delaville, J. 1894-1906. Cartulaire général de l'Orde des Hospitaliers de SaintJean de Jerusalem. Paris.

DP: vid. ALTISENT, A. 1993.

ERITJA, X. 1996. Cartes de població i colonització a l'àrea de Lleida (segona meitat del s. XII-principi del s. XIII). BANGO, I. G. i BUSQUETA, J. J. 1996. "Gombau de Camporrells, bisbe de Lleida. A l'alba del segle XIII". Lleida.

FONT RIUS, J. M. 1949/1985. La reconquista de Lleida y su proyección en el Orden jurídico. "Estudis sobre els drets i institucions locals en la Catalunya medieval", ps. 55-73. Barcelona.

FONT RIUS, J. M. 1953/85. La comarca de Tortosa a raíz de la reconquista cristiana (1148). "Estudis sobre els drets $\mathrm{i}$ institucions locals en la Catalunya medieval", ps. 75-92. Barcelona.

FonT RIUS, J. M. 1969. Cartas de población y franquicias de Cataluña. CSIC. Barcelona-Madrid.

FOREY, A. J. 1973. The templars in the Corona de Aragón. London.

FOREY, A. J. 1984. The Military Orders and the Spanish Reconquest in the Twelfth and Thirteenth Centuries. "Traditio", 40, ps. 197-234.

Forey, A. J. 1992. Els Templers de la Corona d'Aragó i la reconquesta. "L'Avenç", 161, ps. 24-27.

GofFART, W. 1980. Barbarians and Romans, A.D. 418-584. The techniques of Accomodation, Princeton Universy Press.

GonZalvo, G. 1994. Les constitucions de pau i treva de Catalunya (segles XI-XIII). Dep. Justícia Generalitat de Catalunya. Barcelona.

HIESTAND, R.: 1972-84. Papsturkunden für Templer und Johanniter, Vorarbeiten zum Oriens Pontificius, vols. I i II. “Abhandlungen der Akademie der Wissenschaften in Göttingen”, 77 i 135, respectivament. Göttinge.

ImPeriale Di SANT'Angelo, C. 1936. Codice diplomatico della Repubblica di Genova, I, Roma. 
Ledesma, M. L. 1964. Notas sobre la actividad militar de los Templarios. "Principe de Viana", 94-95, ps. 51-56. Pamplona.

Ledesma, M. L. 1967. Pedro López de Luna, maestre de la Orden del Hospital en Aragón y Cataluña. "Estudios de Edad Media de la Corona de Aragón", 8, ps. $417-$ 474. Zaragoza.

Lema Pueyo, J. M. 1990. Colección diplomática de Alfonso I de Aragón y Pamplona. Fuentes Documentales Medievales del País Vasco, 27, San Sebastián.

LFM: vid. MIQUEL, F.

Lladonosa, J. 1955. La ciutat de Lleida, vol. I. Barcelona.

LlADONOSA, J. 1990. La conquesta de Lleida. Barcelona.

LladonosA, J. 1991. Història de Lleida, vol. I. Lleida.

MASSIP, J.: 1984. La gestació de les Costums de Tortosa. Tortosa.

MiQuel, F. 1945. Liber Feudorum Maior. Cartulario real que se conserva en el Archivo de la Corona de Aragón. CSIC. Barcelona.

Miret i SANS, J. 1910. Les cases de Templers i Hospitalers en Catalunya. Barcelona.

OrtegA, P. 1986-87. La carta de población de la Pobla de Massaluca (1294). “Acta Historica et Archaeologica Mediaevalia", 7-8, ps. 193-204. Barcelona.

ORTEGA, P. 1991. Un nuevo documento repoblacional de la Ribera d'Ebre (Tarragona): la carta de población de Rasquera (1206). "Miscel.lània d'homenatge al P. Agustí Altisent”, ps. 519-528. Tarragona.

Pagarolas, L. 1984. La Comanda del Temple de Tortosa. Primer periode (11481213). Tortosa.

PAGAROLAS, L. 1994. Els senyorius templers de les terres de l'Ebre. Significació $i$ sintesi. "Actes de les primeres jornades sobre els Ordes Religioso-militars als Països Catalans (segles XII-XIX)”, ps. 54-66. Tarragona.

Pons MARQués, J. M.: 1938. Cartulari de Poblet. Edició del manuscrit de Tarragona. Institut d'Estudis Catalans, Barcelona.

Sánchez Casabón, A. I. 1995. Alfonso II, rey de Aragón, Conde de Barcelona y marqués de Provenza. Documentos (1162-1196). Fernando el Católico. Zaragoza. SANS i TRAVÉ, J. M. 1977. Alguns aspectes de l'establiment dels templers a Catalunya: Barberà. "Quaderns d'Història Tarraconense”, I, ps. 9-58. Tarragona. SANS i Travé, J. M. 1994. L'Orde del Temple als Països Catalans: la seva introducció $i$ organització (segles XII-XIV). "Actes de les primeres jornades sobre els Ordes Religioso-militars als Països Catalans (segles XII-XIX)”, ps. 17-42. Tarragona.

SANS i TRAvé, J. M. 1996. Els Templers Catalans. De la rosa a la creu. Lleida. SHIDELER, J. C. 1987. Els Montcada: una família de nobles catalans a l'edat mitjana (1000-1230). Barcelona.

Villanueva, J. L. 1806. Viaje literario a las Iglesias de España. Vol. 5. Madrid. 
VIRGILI, A. 1993. El delme i la primícia al bisbat de Tortosa. "I Congrés d'història de l'església catalana. Des dels orígens fins ara”. Actes 1, ps. 423-431. Solsona. VIRGILI, A. 1994. Les relacions entre la Catedral de Tortosa i els Ordes Religiosomilitars durant el segle XII, segons el "Cartulari de la Catedral de Tortosa", "Actes de les primeres jornades sobre els Ordes Religioso-militars als Països Catalans (segles XII-XIX)", ps. 67-79. Tarragona.

VIRGILI, A. 1997. Diplomatari de la catedral de Tortosa (1062-1193). Fundació Noguera. Barcelona.

\section{RÉSUMÉ}

En novembre 1143, le comte de Barcelone Ramon Berenguer IV et l'Ordre du Temple ont signé un accord à fin de résoudre la controverse née du testament d'Alphonse le Batailleur, roi d'Aragon. Dans une des dispositions le comte promettait à l'Ordre le cinquième des conquêtes futures. Les historiens ont interprété qu'il s'agit d'une cinquième part des terres. Cet article suggère une interprétation différente: le cinquième ne fait pas référence au territoire, mais à une participation des revenus qui seront perçus dans les régions d'al-Andalus que le comte et les Templiers vont conquerir a l'avenir. Cette procédure paraît évidente à Tortose et à Lérida, les premières conquêtes après le pacte, ou on n'a pas rédigé de documents concernant la concession de terres et, par contre, l'Ordre a engagé la formation d'un vaste domaine patrimonial. Mais, eventuellement, le cinquième pourrait adopter un critère territorial. Dans ce cas, cela figurait par écrit, comme à la Ribera d'Ebre. L'interventions de l'Ordre dans la colonisation fut différente selon la façon de recevoir le cinquième.

\section{SUMMARY}

In November 1143, Ramon Berenguer IV, Count of Barcelona, and the Order of the knights Templar signed an agreement to solve the dispute caused by the will of the Aragonese king Alfonso the Battler. In one of his arrangements, the Count promised the Order the fifth of future conquests. Historians have considered it as the fifth part of the lands. This article suggests a different interpretation: the fifth is not related to any territory distribution but to a revenues one which would be collected in all the al-Andalus regions to be conquered by the Count and the Templars from then on. This seems to have taken place in Tortosa and Lleida where the Order started very quickly to acquire important domain, although no documents about land grants were written during the first conquests after the above mentioned agreement. Nevertheless, the fifth coult eventually adopt a territorial approach and in such a case, it was registered, as it happened in the Ribera d'Ebre. The intervention in the colonization by the Order could be different according to the way of receiving the fifth. 